\title{
The cell: locus or object of inquiry?
}

\author{
William Bechtel \\ Department of Philosophy, the Center for Chronobiology, and the Science Studies Program, University of California, San Diego, 9500 Gilman Drive, La Jolla, CA 92093-0119, USA
}

\section{A R T I C L E I N F O}

\section{Keywords:}

\section{Cell biology}

Cell theory

Circadian rhythms

Decomposing mechanisms

Mechanistic explanation

Recomposing mechanisms

\begin{abstract}
A B S T R A C T
Research in many fields of biology has been extremely successful in decomposing biological mechanisms to discover their parts and operations. It often remains a significant challenge for scientists to recompose these mechanisms to understand how they function as wholes and interact with the environments around them. This is true of the eukaryotic cell. Although initially identified in nineteenth-century cell theory as the fundamental unit of organisms, researchers soon learned how to decompose it into its organelles and chemical constituents and have been highly successful in understanding how these carry out many operations important to life. The emphasis on decomposition is particularly evident in modern cell biology, which for the most part has viewed the cell as merely a locus of the mechanisms responsible for vital phenomena. The cell, however, is also an integrated system and for some explanatory purposes it is essential to recompose it and understand it as an organized whole. I illustrate both the virtues of decomposition (treating the cell as a locus) and recomposition (treating the cell as an object) with recent work on circadian rhythms. Circadian researchers have both identified critical intracellular operations that maintain endogenous oscillations and have also addressed the integration of cells into multicellular systems in which cells constitute units.
\end{abstract}

(C) 2010 Elsevier Ltd. All rights reserved.

When citing this paper, please use the full journal title Studies in History and Philosophy of Biological and Biomedical Sciences

\section{Introduction}

The cell has figured prominently in the highly successful project of mechanistic research in the life sciences over the past two centuries. Indeed, cell biology is one of the most successful mechanistic sciences. But, ironically, the cell itself does not figure prominently as an explanatorily relevant entity in the field known as cell biology. Rather, it is the locus of many of the mechanisms of interest, not itself a functionally relevant object. In this paper I explore whether this is its inevitable fate as mechanistic science steadily advances to lower levels, or whether there are research projects in which the cell once again serves as the object of inquiry.

What is distinctive of mechanistic science is the project of identifying a mechanism responsible for a phenomenon of interest and then explaining how the mechanism produces the phenomenon by decomposing it into its component parts and operations and showing how the coordinated functioning of these parts and operations generates the phenomenon (Bechtel \& Richardson, 1993). The tools of mechanistic research have been extremely successful in finding parts and operations within mechanisms, but successful explanation of the original phenomenon often requires pairing decomposition with recomposition into the whole mechanism (Bechtel, 2009; Bechtel \& Abrahamsen, 2009). When the parts comprise an integrated whole which functions as a coherent unit and confronts its environment as a unit, then the whole itself is an important object of inquiry. This raises the question of whether the cell itself may be such a unit-does it operate as an integrated whole and engage its environment causally in ways that require that it be treated as an object of inquiry?

In this paper I will describe the project of decomposition that has been so successful, focusing first on the legacies of the cell theory of the nineteenth century and cell biology as it developed in the middle of the twentieth century. At the outset of this history, the cell itself was the focus of inquiry, but was soon eclipsed as researchers took it apart and explored its constituents. As a point of contrast, I will then present in Section 4 a theoretical perspective developed in recent decades that focuses on the minimal properties of living systems. This perspective emphasizes the integration

E-mail address: bill@mechanism.ucsd.edu 
of processes within the cell, rendering the cell as the integrated unit into the object of inquiry. To provide further substance to this analysis, I turn in the last sections (5 and 6 ) to a contemporary example. In the quest to understand circadian rhythms, researchers first identified cells that endogenously maintain daily oscillations. Researchers then decomposed these cells, identifying the genes that exhibit a daily cycle of expression due to feedback loops involving the proteins they generate. As successful as that pursuit has been in the last fifteen years, however, researchers also came to realize that there is considerable variability in the oscillations of individual neurons, and that synchronizing a population of neurons is critical for generating circadian rhythms in organisms. The very success of the enterprise of decomposing the mechanism within the cell into its parts and operations has brought renewed focus on the cell itself as a functional entity within a larger mechanism, which again renders it the object of inquiry.

\section{From cell theory to organelles in the nineteenth century}

The word cell entered scientific discourse as a result of the development of microscopes. In examining cork through an early microscope, Robert Hooke (1665, p. 113) described pores that 'had a very little solid substance, in comparison of the empty cavity that was contain'd between'. He designated them with the Latin word for little rooms, cellulae, and treated their walls as their defining characteristic. In the same period Antony van Leeuwenhoek (1674) reported on bacteria and sperm, and characterized these cells that existed independently of a larger structure as animalcules (little animals). Over the next 150 years, however, the spherical and chromatic aberrations in microscopes with multiple lenses generated considerable controversy. Van Leeuwenhoek and others who employed microscopes with only a single lens avoided these problems, but they confronted limitations in the amount of magnification they could achieve. With compound microscopes, spherical aberrations result from light rays that leave the lens at different distances from the axis, and chromatic aberrations result from light of different wavelengths refracting to different degrees.

Even in the face of these limitations, some investigators embraced the microscope and treated the units they saw as the fundamental units within living organisms. Thus, Henri Milne Edwards and René Joachim Henri Dutrochet (1824) spoke of seeing globules, which they construed as the building blocks of organisms. Others, such as Xavier Bichat (1805), rejected the microscope and limited their anatomical investigations to what they could observe with the naked eye. Bichat developed a classification of types of tissue and treated these as the basic unit for understanding organisms and their pathologies, and refused further to decompose tissues.

Lens makers in the late eighteenth and early nineteenth centuries developed techniques for correcting spherical aberrations and significantly reducing chromatic aberrations. Microscopes employing these lenses became available to researchers in the 1820 s and 1830s and were one factor enabling Matthias Schleiden (1838) and Theodor Schwann (1839) to advance the cell theory, which proclaimed that cells are the basic living units in all organisms. With improved microscopes, Robert Brown (1833, p. 710) had identified the ubiquitous presence of 'a single circular areola, generally somewhat more opake than the membrane of the cell' in his microscopic investigations of orchids. He designated the structure the nucleus, but Schleiden referred to it as the cytoblast in advancing his proposal that it was the structure from which the rest of the cell developed. Schleiden claimed that growth from a cytoblast was the distinctive feature that united the variably appearing anatomical structures in different tissues as cells. Schwann extended this approach to animals, where even greater variability in the appearance of anatomical structures was observed. But as important as the visualization of the nucleus was for the development of the cell theory, more important was the account of the process by which the nucleus formed and how the cell was formed from it.

Schleiden and Schwann differed on the question of whether the process took place within existing cells or in the intercellular fluids, but for both cells formed like crystals through a process of accretion out of the fluid matrix. Basing their account of cell formation on an analogy with a known physical process was critical to both Schleiden and Schwann as they were part of a group of young mechanist physiologists that developed around Johannes Müller (who remained more sympathetic to a vitalist approach than his students). Schwann went on to argue that cells were the basic unit for all metabolic processes (he coined the term metabolism): 'The cause of nutrition and growth resides not in the organism as a whole, but in the separate elementary parts-the cells' (Schwann, 1839, p. 192). This extended his earlier claim (Schwann, 1836) that processes such as fermentation occurred only in living cells, a claim that had rankled other mechanists, especially investigators such as Friedrich Wöhler, who sought chemical accounts of living processes and thought even acknowledging living units as the locus of such processes capitulated to 'vitalism' (Wöhler, 1839). Schwann insisted, however, that these processes occurred in cells as a result of the specific composition of the matter deposited in them as cells formed. He thereby saw himself as extending the mechanistic perspective to physiology generally (Bechtel, 1984).

In subsequent years some investigators focused on the viscous liquid within cells that von Hugo von Mohl (1846) named protoplasm and viewed it as responsible for the activities of cells. For some investigators, such as Max Schultze (1861), protoplasm was more important than the cell boundary in distinguishing cells. Others, however, continued to focus on the cell boundary. This was particularly true of researchers such as Mohl, Nägeli, and Virchow, who rejected Schleiden's and Schwann's accounts of cell formation, and argued that new cells arose from the division of existing cells. For them, the crucial activity was the cell boundary closing in to separate two daughter cells. Whether focusing on metabolism or cell division, however, these early researchers were focused on activities involving whole cells, rendering the cell as a basic physiological unit.

Although van Leeuwenhoek had observed both prokaryotes (bacteria) and eukaryotes, the research giving rise to the cell theory and later to cell biology was performed on eukaryotic cells, in large part due to their larger size and ease of manipulation. ${ }^{1}$ One consequence of focusing on eukaryotes was that, as the organelles were identified within it, beginning in the latter part of the nineteenth century, the cell itself was eclipsed by the organelles. The first to be the focus of inquiry was the nucleus. Robert Remak (1855) described cell division as beginning with the division of the nucleolus, followed by that of the nucleus, and then the division of the cell. Investigation of sub-cellular structures accelerated with the introduction of stains that were selectively absorbed by structures in the cell (carmine red was introduced in the 1850s, with hematoxylin and aniline dyes following in the 1860s), and subsequently with the introduction of apochromatic lenses in 1886 which further minimized chromatic aberrations. Edouard van Beneden (1875) described structures in the nucleus that he called bâtonnets ('little rods') and observed that they moved apart in the process of division.

\footnotetext{
${ }^{1}$ The occurrence of organelles as structural elements in eukaryotic cells continued to render them the cell of choice even as cytology gave way to cell biology, as discussed in

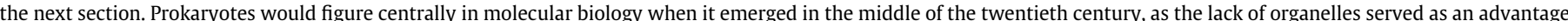

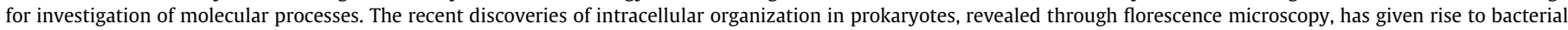
cell biology (see Gitai, 2005, for a review).
} 
Hermann Fol (1873) reported on the configuration of the spindle and astral rays and proposed an analogy with the lines of force found between opposite magnetic poles, suggesting thereby a dynamical perspective. Finally, Walther Flemming (1882) designated the rods chromatin as a result of their absorption of stains and described the overall process of mitosis as initiated by the behavior of the chromatin.

During the same period, investigators began to report on structures found within the cytoplasm, although these reports proved more contentious. Franz Leydig, Jean-Baptiste Carnoy, and Rudolf Heidenhain claimed to identify what they called fibrils, and proposed they accounted for the unusual consistency of protoplasm. Critics such as Flemming, Otto Bütschli, and Alfred Fischer, however, charged that these structures were artifacts generated by the application of stains. Richard Altmann (1890) reported on filaments in the cytoplasm which he argued were the basic living units to which he attributed metabolic processes, especially fat metabolism and secretion. Carl Benda (1899) renamed these filaments mitochondria since sometimes they appeared threadlike and sometimes granular and Leonor Michaelis (1899) showed that they dyed with a reductive stain, suggesting a role in oxidative reactions. But just as many maintained that mitochondria were artifacts of the preparation of cells for microscopy, a charge that was to be echoed until the 1950s. A similar history befell the Golgi apparatus which Camillo Golgi (1898) first described as an internal reticular apparatus. Although many investigators treated it as a real structure in the cell and sought out its function, others, including George Palade and Albert Claude (1949a,b) argued that it was an artifact.

Cytology's golden age was the nineteenth century, when improvements to the microscope and development of staining techniques led to the identification of the cell as the basic unit of living organisms and accounts of cell division. During the first half of the twentieth century there were no comparable advances. Although texts such as Edmund Cowdry's (1924) General cytology and Geoffrey Bourne's (1942) Cytology and cell physiology testify to active continuing inquiry and provide useful reviews of this research, much of what they addressed were contested claims about the reality of organelles. One factor limiting the advance of cytology was that, as a result of their size, organelles within cells are at the limits of resolution for light microscopes. But a more serious factor was that there were limited strategies for linking these structures with functions. The main tool involved establishing correlations between the number of organelles of a certain type in a cell and the activities the cell was performing. This growing focus on organelles, rather than cells themselves, though, is a major characteristic of the usual path of research within cytology.

\section{The creation of the modern discipline of cell biology}

During the same period as cytology was stagnating, a new discipline, biochemistry, was emerging, empowered by tools for manipulating chemical reactions within cells and enabling the articulation of reaction pathways figuring in cell processes. The elucidation of the mechanism of glycolysis (fermentation) represented a major success story (Bechtel, 1986). Biochemical techniques, however, began by homogenizing the contents of cells and putting them into aqueous media. Having destroyed the membranes segregating cell organelles, biochemistry was unable to provide information about how the chemical reactions it identified related to cell structure. As a result, a no-man's land existed between large cell structures that could be viewed under the microscope and macromolecules that could be investigated biochemically (de Duve, 1963-1964).

Two new techniques introduced into biology in the 1930s and 1940s allowed a subsequent generation of researchers to investi- gate structures at this size-scale. Cell fractionation, pioneered by Robert Bensley and refined by Claude, separated the contents of cells by centrifugal force into fractions of different masses (Fig. 1). This enabled linking particles of different masses (in the four fraction technique developed by Claude (1940) these corresponded roughly to the nucleus, the mitochondrion, the endoplasmic reticulum, and the cytoplasm) with different chemical reactions. For example, the mitochondrion was soon linked to oxidative reactions through the presence in its fractions of succinoxidase and cytochrome oxidase (Hogeboom et al., 1946). Electron microscopy, first employed for the study of cell structure by Keith Porter, Claude, and Erenst Fullam (1945) and refined by Porter, Palade, Fritiof Sjöstrand, and others in the following decade, enabled the identification of structures below the resolution of the light microscope (Fig. 2). Even more important, it could reveal detail of the structures, such as the infoldings of the inner membrane of the mitochondria which Palade (1952) labeled cristae. By combining these techniques it became possible, for example, to localize key steps in oxidative metabolism either in the mitochondrial matrix or on the cristae. With these structure-function linkages in place, it no longer seemed reasonable to treat the mitochondrion as an artifact. Although the history is a bit more complicated, the Golgi apparatus became associated with processes involved in preparing newly synthesized proteins for export, and Palade, who had been one of the last skeptics, admitted its reality and was awarded the Nobel Prize in part for his work on the Golgi apparatus (Jamieson \& Palade, 1966). Likewise, the endoplasmic reticulum, first identified as a lacelike reticulum in electron micrographs (Porter et al., 1945), and the ribosomes located within it, were identified as the locus of protein synthesis (Palade \& Siekevitz, 1955), and the lysosome, another organelle discovered with the electron microscope, was associated with hydrolytic enzymes that decompose aging organelles and other waste products (Novikoff et al., 1956). Compared to these cytoplasmic organelles, which were either unknown before the application of these new techniques, or whose existence was challenged, electron microscopy and cell fractionation generated far less radical advances in the understanding of the nucleus, but did help reveal such things as pores in the nuclear membrane and allow quantitative measurements of DNA content of the nucleus. (I discuss the new knowledge of cell structure and function provided by these new techniques in more detail in Bechtel, 2006, Chs. 5 and 6.)

The period from 1945 to 1965 was one of great success in studying cells, in which the cell once again moved to the forefront in the biological sciences and a discipline named 'cell biology' was established. As the number of researchers who began to utilize cell fractionation and electron microscopy in their research increased, new journals were created that made cell or cytology part of their name: Experimental Cell Research in 1950, the International Review of Cytology in 1952, and the Journal of Biochemical and Biophysical Cytology in 1955. New professional societies were also created that employed cell biology in their name: The International Society for Cell Biology in 1947 and the American Society for Cell Biology in 1961. In 1962 the Journal of Biophysical and Biochemical Cytology changed its name to the Journal of Cell Biology, and became associated with the American Society for Cell Biology. (For more details on the development of these institutions, see Bechtel, 2006, Ch. 7.)

Even as cell biology became a significant biological discipline, researchers who self-identified with the discipline did not treat the cell as a unit that figured in explanations but rather as a locus where a host of physiological processes occurred. There was little focus on the integration of operations performed in multiple cell organelles as research concentrated on molecular and biochemical processes within individual organelles. Soon even organelles ceased to be the object of study, and became merely the locus of chemical reactions. Cell biology itself became elided with molecular biology 


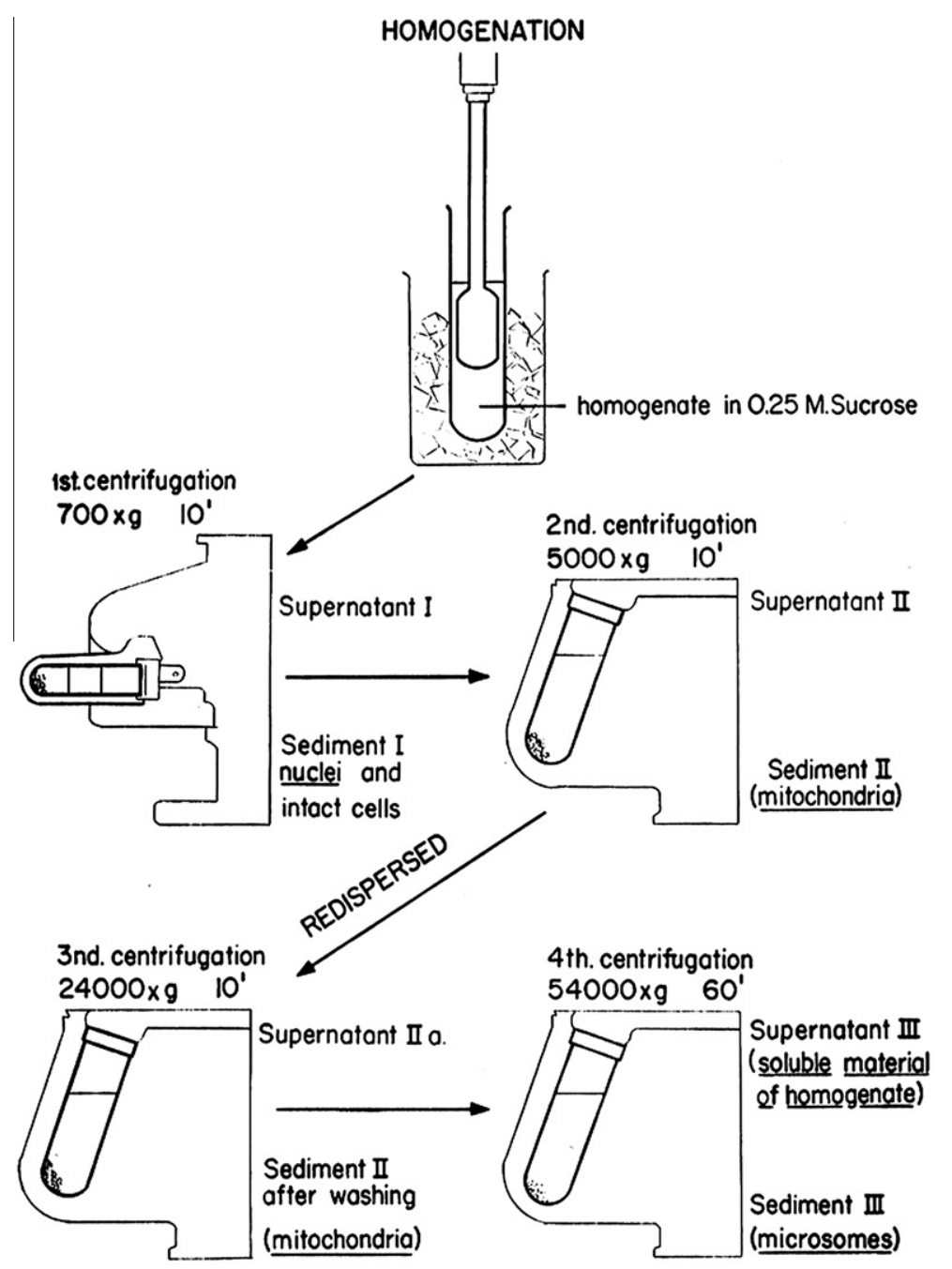

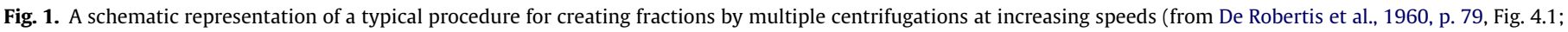
used with permission).

and references to 'cell and molecular biology' became increasingly common (e.g., in the names of academic departments). In contrast to the discipline of cell biology, other biological disciplines, such as microbiology and cytopathology (sometimes referred to as cytology), did maintain a focus on the cell as a unit. Moreover, other techniques for studying cells, such as tissue or cell culture, retained the cell as the object of manipulation.

\section{An alternative perspective: the cell as an integrated, autonomous system}

Even as the core of mechanistic research has come to regard the cell as merely a locus of biochemical and molecular processes, which themselves serve to explain the phenomena once associated with cells, a variety of theorists, interested in fundamental characterizations of living systems, have advanced a different perspective in which the cell once again becomes a central object of study. I will identify several threads in this theorizing, each of which focuses on the way in which living systems (with the cell being the most basic) are organized as integrated wholes. It should be noted from the outset that, as theorists, many of these scientists did not contribute to and were often critical of laboratory research in biology. They have often had more uptake among those pursuing mathematical and computational modeling of living systems than those conducting experimental inquiries leading to the identification of the parts and operations in cell mechanisms.

One thread of this alternative perspective is found in Robert Rosen (1991), who addressed the necessity of cells as living systems to repair themselves. Rosen argued that the requirement of self-repair was incompatible with living entities being mechanisms, since mechanisms are always open to external efficient causation, whereas a system that repairs itself will be 'closed to efficient causation'. The cartoons in Figure 3 illustrate Rosen's conception of what such a system must be like. Open arrows represent efficient causation and closed arrows material transformations. On the top is a representation of a metabolic process in which $f$ is the efficient cause responsible for metabolizing A into B. But $f$ will be in need of repair. Rosen proposes that $B$ might provide the material used to repair $f$, but that requires an efficient cause outside the current mechanism, $\Phi$. Now $\Phi$ is in need of a procedure for repair, and Rosen proposes that $f$ might provide the material cause for this repair, and B might serve as the efficient cause. The result is a system closed to efficient causation (all efficient causes are part of the system) but open to material causation, since A must be generated from something. Although Rosen doesn't emphasize it, such a system must be energetically open. Rosen's claim that a system closed to efficient causation is not a mechanism depends upon viewing mechanisms as only responsive to external efficient causes. The 


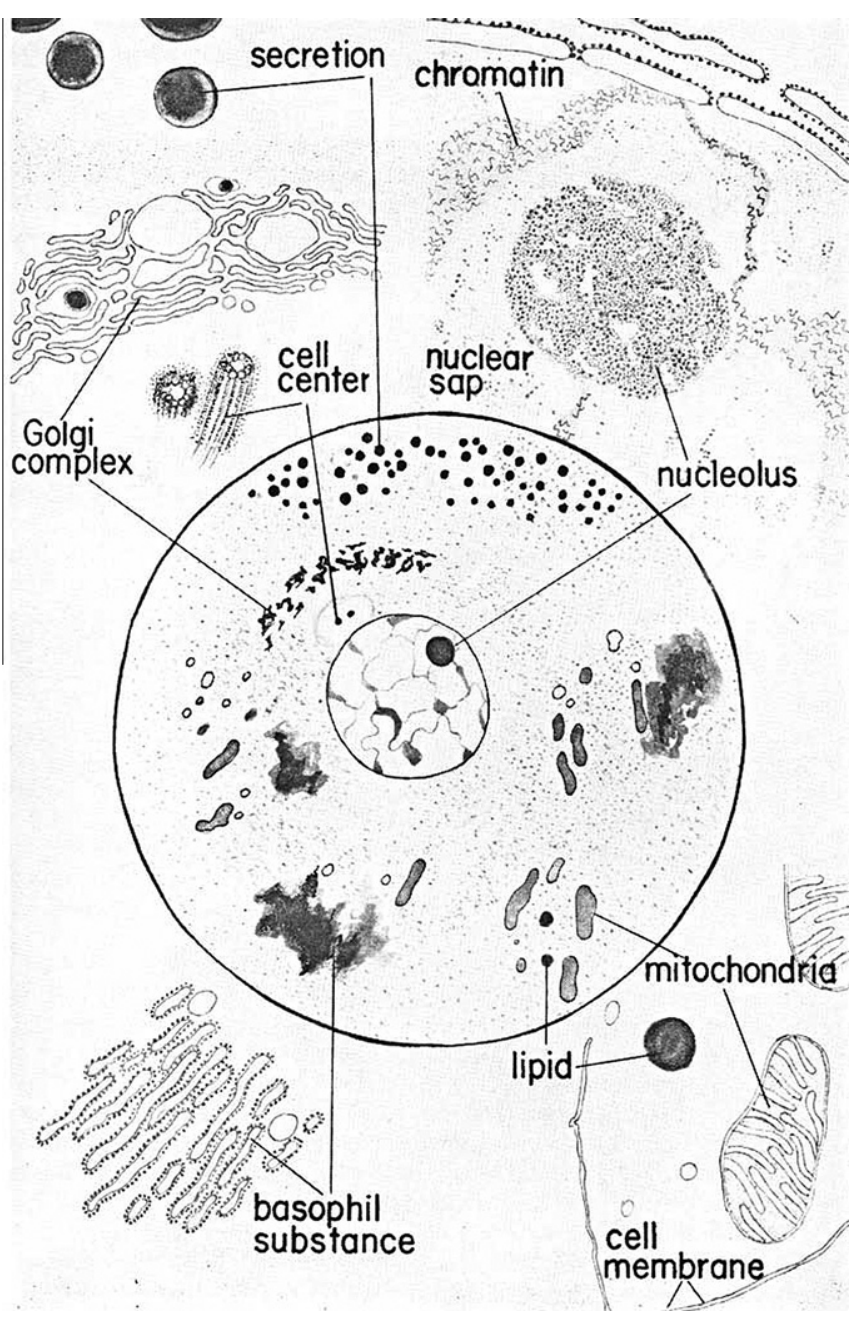

Fig. 2. A representation of cell structure detail available in light versus electron micrographs (from De Robertis et al., 1960, p. 71, Fig. 3.9; used with permission). The center shows what can typically be seen with a light microscope, whereas the outer region reveals details of various organelles that could be seen in electron micrographs of the 1950 s.

noteworthy difference between the system on the top and that on the bottom is the complexity of the organization in the system on the bottom, and increasingly mechanistic scientists are considering such complex modes of organization (Bechtel \& Abrahamsen, 2011).

A related thread is found in Francesco Varela's theorizing about living systems that maintain themselves 'through the active compensation of deformations' (Varela, 1979, p. 3). In his treatment, Varela builds upon Cannon's (1929) conception of homeostasis, the idea that living systems are organized to return to a target condition whenever perturbed. He does this in two steps, first 'making every reference for homeostasis internal to the system itself through mutual interconnections of processes' and second 'by positing this interdependence as the very source of the system's identity as a concrete unity which we can distinguish' (Varela, 1979, pp. 12-13). In other words, all homeostatic operations in organisms are efficiently caused from within the system and it is the continued existence of the set of causally dependent processes that constitutes the continued existence of the system. In terms of these ideas, he introduces his concept of autopoiesis:

An autopoietic system is organized (defined as a unity) as a network of processes of production (transformation and destruction) of components that produces the components that: (1)
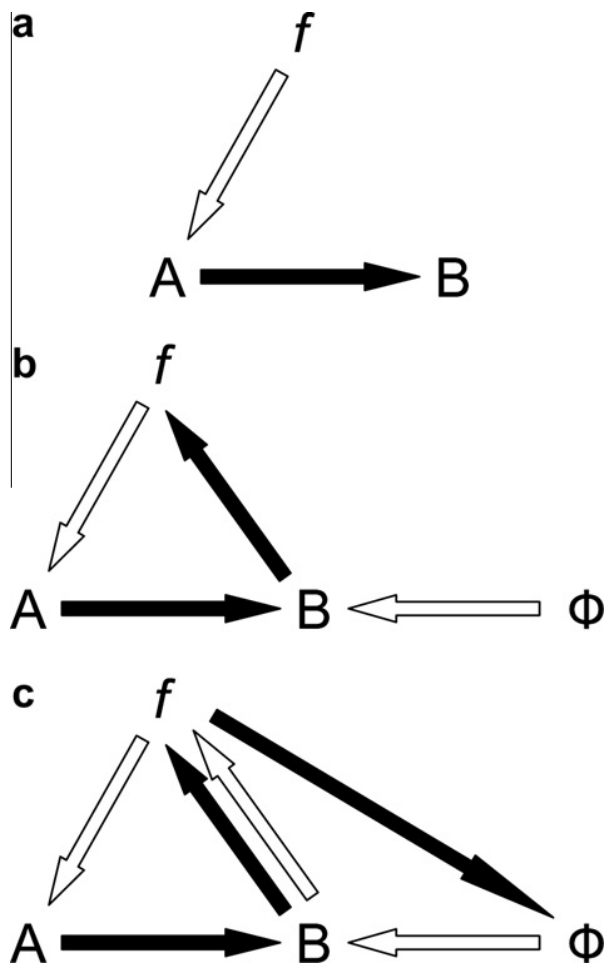

Fig. 3. Cartoons of three modes of organization described by Rosen (figures adapted by the author from Rosen, 1991, pp. 249 ff.). The first two systems are open to efficient causes (open arrows) since $f$ and $\Phi$ respectively are not produced by efficient causes within the system transforming other entities (black arrows) within the system. The diagram on the bottom represents a system closed to efficient causation as all efficient causes are themselves produced (materially and efficiently) from within the system.

through their interactions and transformations continuously regenerate and realize the network of processes (relations) that produce them; and (2) constitute it (the machine) as a concrete unity in the space in which they exist by specifying the topological domain of its realization as such a network. (Ibid., p. 13; see also Maturana \& Varela, 1980)

For Varela, the cell is the basic autopoietic system. By focusing on how the coordinated activity within an autopoietic system enables the system to maintain its identity, Varela's framework focuses attention back on the cell itself and not just on the operations occurring within it. Maturana and Varela (1980) applied the concept of autopoiesis beyond cells to whole organisms (and especially to cognitive systems) while others have extended the idea further to social systems, arguing that the same conceptual tools apply to a wider range of systems. Their most fundamental application, though, is to the cell, and so it is appropriate to view the concept as illuminating the understanding of the cell as the fundamental living unit.

Yet another thread is found in the Hungarian chemist Tibor Gánti's attempt to describe the simplest chemical system, which he called a chemoton, capable of exhibiting the characteristics of life (see Gánti, 2003, for a systematic statement of the proposal which he initially advanced in the 1970s; for a detailed exposition of Gánti's view, see Griesemer \& Szathmáry, 2008). These characteristics of life he identified as being systems constructed of soft (e.g., macromolecules), not hard (e.g., metallic) components, that construct themselves, grow, multiply, and evolve. At the core of his chemoton Gánti hypothesized a metabolic system that continually regenerates itself in the manner of the citric acid cycle discovered by Krebs. In the citric acid cycle, a product of a reaction sequence, oxaloacetic acid, combines with new input to generate 
a

$$
A+X \longrightarrow 2 A+T+Y
$$

b

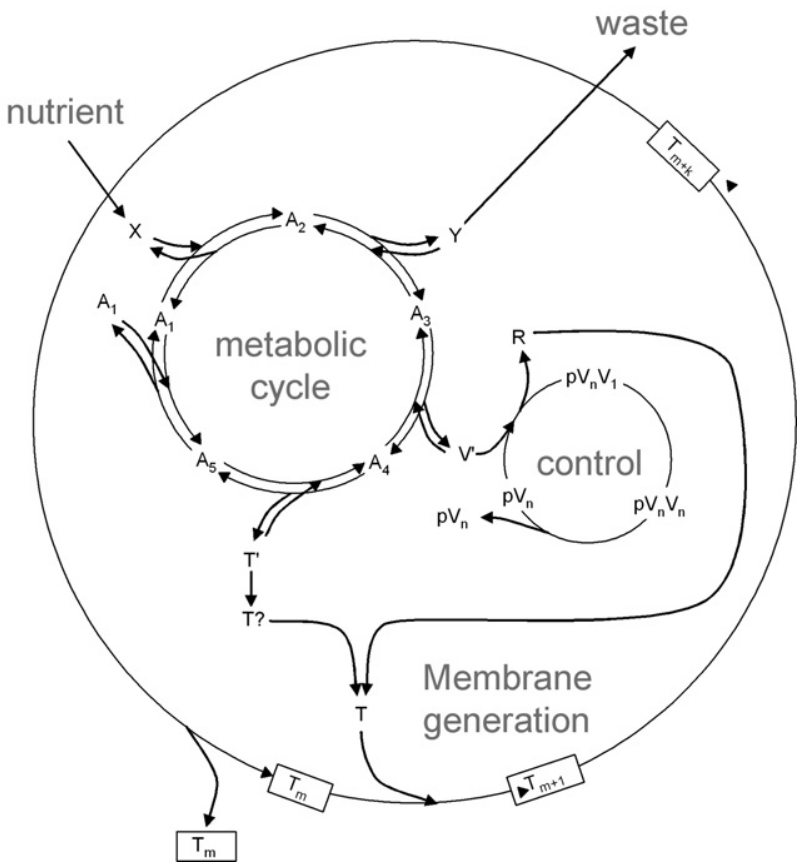

Fig. 4. TOP: Gánti's conceptualization of the basic metabolic cycle, where $A$ represent the components of the cycle, $\mathrm{X}$ the reactants entering the cycle, $\mathrm{T}$ the components of the membrane generated by the cycle, and $\mathrm{Y}$ the reaction products (adapted by the author from Gánti, 2003, p. 104). The generation of $2 \mathrm{~A}$ in each iteration of the cycle represents the continual growth achieved by the cycle. BOTTOM: Gánti's hypothesized chemoton, consisting of a metabolic cycle, a membrane generation mechanism, and a control system, appropriately connected to one another to form an integrated system (adapted by the author from Gánti, 2003, p. 4).

citric acid, which constitutes the start of the sequence. Gánti construed his metabolic cycle as autocatalytic so that it continually makes more of the starting components as well as additional products, some of which are used to build an enclosing membrane, according to the stoichiometric relation shown at the top in Figure 4.

A system consisting of an autocatalytic metabolic engine and a membrane, Gánti hypothesized, would both remake itself from incoming metabolites and grow. He suggested further that the membrane would grow faster than the metabolic material, and this would lead to it closing in upon itself and budding, thereby reproducing. Gánti proposed that the membrane would also serve as a boundary, differentiating the system from its environment and regulating the incorporation of material $(A)$ from the environment and the expulsion of waste $(\mathrm{Y})$ back into the environment. Notice that these two components are systemically integrated-while the membrane is generated by the metabolic system, it regulates the environment in which the metabolic system operates. Understanding this integration requires not just analyzing the component systems, but the organization relating them.

Gánti summarized what such a system would be able to do:

It is separable from the external world and its internal composition differs from that of the environment. It continuously consumes substances that it needs from the environment which are transformed in a regulated chemical manner into its own body constituents. This process leads to the growth of spherule; as a result of this growth, at a critical size the spherule divides into two equal spherules, both of which continue the process. (Gánti, 2003, p. 105)

According to Gánti, this system required another component to exhibit the properties of life: a control system that is capable of storing information. He introduced such a control system by having the metabolic system also add a monomer to a polymer that is built along an existing polymer template. The length of the polymer is thereby able to carry information about the number of cycles completed, which could be used in regulating the system's behavior. These three systems then comprised the chemoton (Fig. 4b). What is important in Gánti's account is his focus on how the whole chemoton, rather clearly modeled on biological cells, is integrated to work together to achieve the features of continually reconstructing itself, growing, and replicating. These are not activities of individual components of the chemoton (or of individual components of a cell), but of the interacting whole.

These various threads come together in the idea that living systems, including cells, are autonomous systems. Varela himself introduced the idea of autonomy through his account of autopoiesis: 'Autopoietic machines are autonomous: that is, they subordinate all changes to the maintenance of their own organization, independently of how profoundly they may be otherwise transformed in the process' (Varela, 1979, p. 15). What is missing in Varela's analysis, and indeed in those of Rosen and Gánti, is an explicit focus on the thermodynamics. It is particularly noteworthy of living systems that they exist far from thermodynamic equilibrium with their environment and either maintain themselves in such a state or cease to exist as living systems. ${ }^{2}$ The features of self repair, autopoiesis, growth, and replication, are not incidental to living systems, but fundamental to the kind of entities they are. Since the tendency of systems out of equilibrium is to approach equilibrium, living systems must constantly recruit matter and energy from sources in their environment and use these resources to construct and repair themselves, including the boundary conditions that separate themselves from their environment, and expel their waste products back into the environment. Incorporating this thermodynamic perspective with the conception of self-construction and repair, Kepa Ruiz-Mirazo, Juli Peretó, and Alvaro Moreno (2004) characterize an autonomous system as

a far-from-equilibrium system that constitutes and maintains itself establishing an organizational identity of its own, a functionally integrated (homeostatic and active) unit based on a set of endergonic-exergonic couplings between internal self-constructing processes, as well as with other processes of interaction with its environment. (Ruiz-Mirazo et al., 2004, p. 330)

Achieving autonomy requires the coordinated operation of the whole living system so as to manage the flow of matter and energy through the system, not just the independent operation of parts. In particular, temporal integration becomes important, and operations must be orchestrated to occur at the appropriate time to be related to other operations in the cell (Bechtel \& Abrahamsen, 2011). Insofar as cells appear to be the simplest autonomous systems, this theoretical perspective treats the integrated cell once again the focus of theoretical understanding as it was in the original cell theory of Schleiden and Schwann.

The perspectives advanced in this section have been conceptual and theoretical rather than grounded on experimental inquiry. The recent development of synthetic biology-the project of trying to

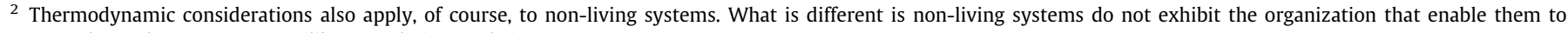
maintain themselves in a non-equilibrium relation to their environment.
} 
build systems that exemplify biological phenomena one is trying to understand from simpler components-provides a context for linking such conceptual contributions with experimental investigation. As an illustration, Pier Luisi (2006) has pursued a project of constructing a minimal cell by inserting enzymes and other macromolecules into lipid vesicles. The minimal cell is intended to consist of the smallest number and simplest components that can, when composed into a system, exhibit properties of lifeself-maintenance (metabolism), self-reproduction, and evolvability. The first two properties clearly echo the themes advanced by the theorists discussed above (Luisi explicitly discusses Varela and Maturana as well as Gánti). Luisi and his collaborators have succeeded in incorporating in lipid vesicles the components required to synthesize the green fluorescence protein (GFP), chosen since the success of the project can be ascertained by the resulting fluorescence. In an earlier project, they inserted the components of the chemical pathway that converts glycerol-3-phosphate to phosphatidylcholine, a major component of lecithin. This represents an important step towards building a lipid vesicle which manufactures its own membrane boundary, thereby realizing a version of autopoiesis. Although these successes to date represent only initial steps towards building a minimal cell, they do indicate how the theoretical perspectives discussed above can be integrated into experimental research.

\section{A recent example: decomposing the circadian oscillator}

The question of whether the cell should merely be the locus for studying biological processes, or is sometimes itself the appropriate object of inquiry remains an important one. The strategy of decomposing cells to identify their parts and operations has been extremely productive and is likely to remain so. But equally important for explaining many biological phenomena is developing an understanding of how whole cells (and whole organisms) are organized so as to function as coordinated autonomous entities that engage other entities in their environments. In this section and the next I explore how these issues are playing out in contemporary research on circadian rhythms. A noteworthy feature of this research and much other research in contemporary biology is that it is phenomenon driven and integrates research tools and perspectives from a variety of disciplines as required. In this research, disciplines such as cell biology or molecular biology are less central in setting the research agendas than in earlier epochs in biology.

Living on our rotating planet requires organisms to coordinate temporally their physiological processes and behaviors with the day-night cycle. Organisms relying on photosynthesis for energy must perform the necessary operations during daylight hours. If they also need to perform operations that are harmed by the oxygen generated during photosynthesis, they need to perform these at night. All animals appear to require sleep, and organisms that are easy prey for others are best served by timing their waking activities to the sleep pattern of their predators. Other factors, such as temperature and humidity, vary systematically with time of day. Accordingly, fruit flies need to time their eclosion from their pupae to early morning when the temperature is low and humidity is high. Many of these activities can only be performed at the optimal time if preparatory steps are taken in advance. Accordingly, it is not surprising that most life forms on the planet, from bacteria and fungi to plants and animals, endogenously maintain rhythms with a period of approximately twenty-four hours (circadian from cir$\mathrm{ca}+$ dies) that enable them to track time of day. The fact that these rhythms are maintained endogenously is demonstrated by the fact that they are sustained when time cues, Zeitgebers such as the onset and offset of daylight, changes in temperature, and so on, are eliminated and organisms are subjected to a constant environment. Moreover, a vast range of physiological and behavioral processes are modulated by these endogenous rhythms.

A first challenge in understanding how multi-cellular organisms maintain endogenous twenty-four-hour rhythms is to identify where such timekeeping is performed. Research on mammals that began in the 1970s identified the suprachiasmatic nucleus (SCN), a bilateral structure consisting (in mice) of 8,000 to 10,000 neurons in each hemisphere, as the locus of the central clock. Lesions to the SCN result in elimination of behavioral rhythms (Moore \& Eichler, 1972), transplants of the SCN can restore rhythms in organisms rendered arrhythmic by lesions to the SCN (Ralph et al., 1990), and SCN explants maintained in culture can generate circadian rhythms (Welsh et al., 1995). In Drosophila, which have also figured prominently in circadian research, a set of lateral neurons were found to perform the central timekeeping function.

Having identified individual cells as the locus of the mechanism responsible for endogenous circadian oscillations, the next step was to decompose this mechanism into its parts and operations. Ronald Konopka (Konopka \& Benzer, 1971) made the first contribution when he created mutant flies with either shortened or lengthened periods of oscillation, or which became arhythmic. He named the affected gene period (per). With the advent of cloning in the 1980s Jeffrey Hall, Michael Rosbash and their colleagues were able to measure per's mRNA transcript and the resulting protein, and these were shown to oscillate with an approximately twenty-fourhour period, with the peak in protein concentration lagging several hours behind the peak in mRNA concentration. This led Paul Hardin, Hall, and Rosbash (1990) to propose a negative feedback mechanism (Fig. 5) in which per is transcribed into per mRNA in the nucleus, then transported to the cytoplasm where it is translated into the protein PER. PER is subsequently transported back into the nucleus, where it was hypothesized to inhibit its own transcription in one way or other. This reduces the rate of formation of new PER, and if PER also

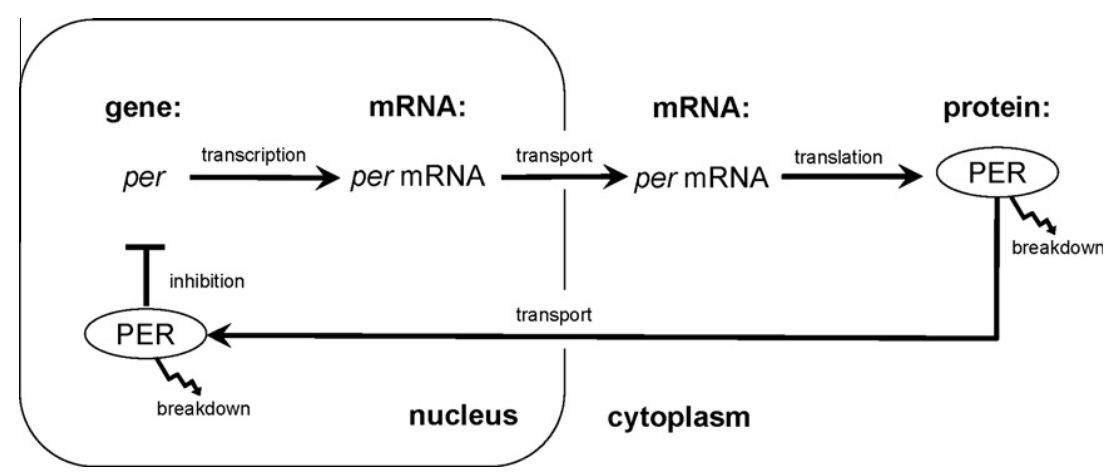

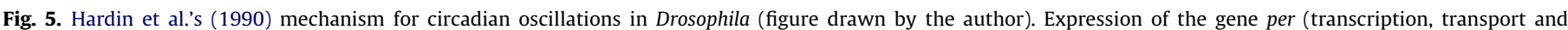

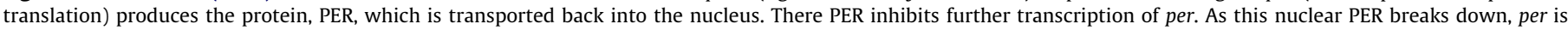
released from inhibition and a new turn of the cycle begins. 
is gradually broken down, its concentration will drop. As the concentration of PER in the nucleus drops the gene will be released from inhibition, and more PER will be synthesized. As a result, the concentration of PER will continually fluctuate.

From this initial sketch of the mechanism, circadian researchers rapidly discovered a host of additional components of the SCN cells. Of particular importance was the determination of how PER operates on its own DNA-by forming a dimer with another protein, CRY, and then reacting with another dimer composed of CLK and BMAL1. When unbound, the CLK:BMAL1 serves as a activator of per transcription but when bound with PER:CRY, it ceases to play that role. It was further determined that there were at least two feedback loops, one positive and one negative, as well as processes through which light could affect the clock via a photopigment such as melanopsin (see Fig. 6 for a sketch of the mammalian mechanism as currently understood). In the last few years researchers have decomposed the processes within the mechanism even further, by, for example, discovering that CLK is also an acetyltransferase and so enhances the ability of DNA to be transcribed by adding acetyl groups to it, a process known chromatin remodeling (Doi et al., 2006).

Research on circadian rhythms reflects the same pattern of research on cells I sketched above. Investigations began by treating cells within the SCN as the pertinent unit that exhibited endogenous oscillations. But the investigations soon left the cell itself behind as clues to the responsible mechanisms within cells were found and investigators focused on the parts (genes and proteins) and the operations they performed. This research that decomposes the mechanism responsible for endogenous circadian rhythms has been enormously successful, and the research is increasingly probing even deeper into the components of the circadian oscillators within cells. The cell appears again as only the locus for the responsible chemical mechanism.

\section{A recent example continued: recomposing the circadian oscillator}

As successful as the endeavor of decomposing circadian oscillators has been in identifying their parts and operations, it has also proven important to recompose them to understand how they are organized so as to generate twenty-four-hour oscillations. One step in this process is to develop mathematical and computational models to ascertain whether the operations identified, when they are organized in positive and negative feedback loops such as those pictured in Figure 6, will in fact generate the phenomenon. This is usually done by writing differential equations that describe how components in the system change as a result of other components, and using these to simulate the operation of the mechanism. Jean-Christophe Leloup and Albert Goldbeter (2003) advanced one such model of the proposed mechanism in mammalian SCN cells that indicated it would generate sustained rhythms and be appropriately entrainable by light, and other researchers have developed models to account for specific circadian phenomena (for discussion, see Bechtel \& Abrahamsen, 2010). An alternative strategy, pioneered by Michael Elowitz and Stanislaw Leibler (2000) is to synthesize an oscillatory system by inserting genes that implement a feedback loop that regulates the expression of green florescent protein into E. coli. The synthesized system they created generated sustained oscillations, but with a different period and less regular than those in naturally occurring circadian oscillators.

A surprise encountered in the research, however, has pushed researchers to focus not just on the complex network of reactions within cells, but whole cells and their interactions. When David Welsh, Diomedes Logothetis, Markus Meister, and Steven Reppert (1995) dispersed neurons from the SCN of mice on multielectrode grids, they found that while individual SCN cells continued to oscillate (the major objective of their study), they do so in varying peri-

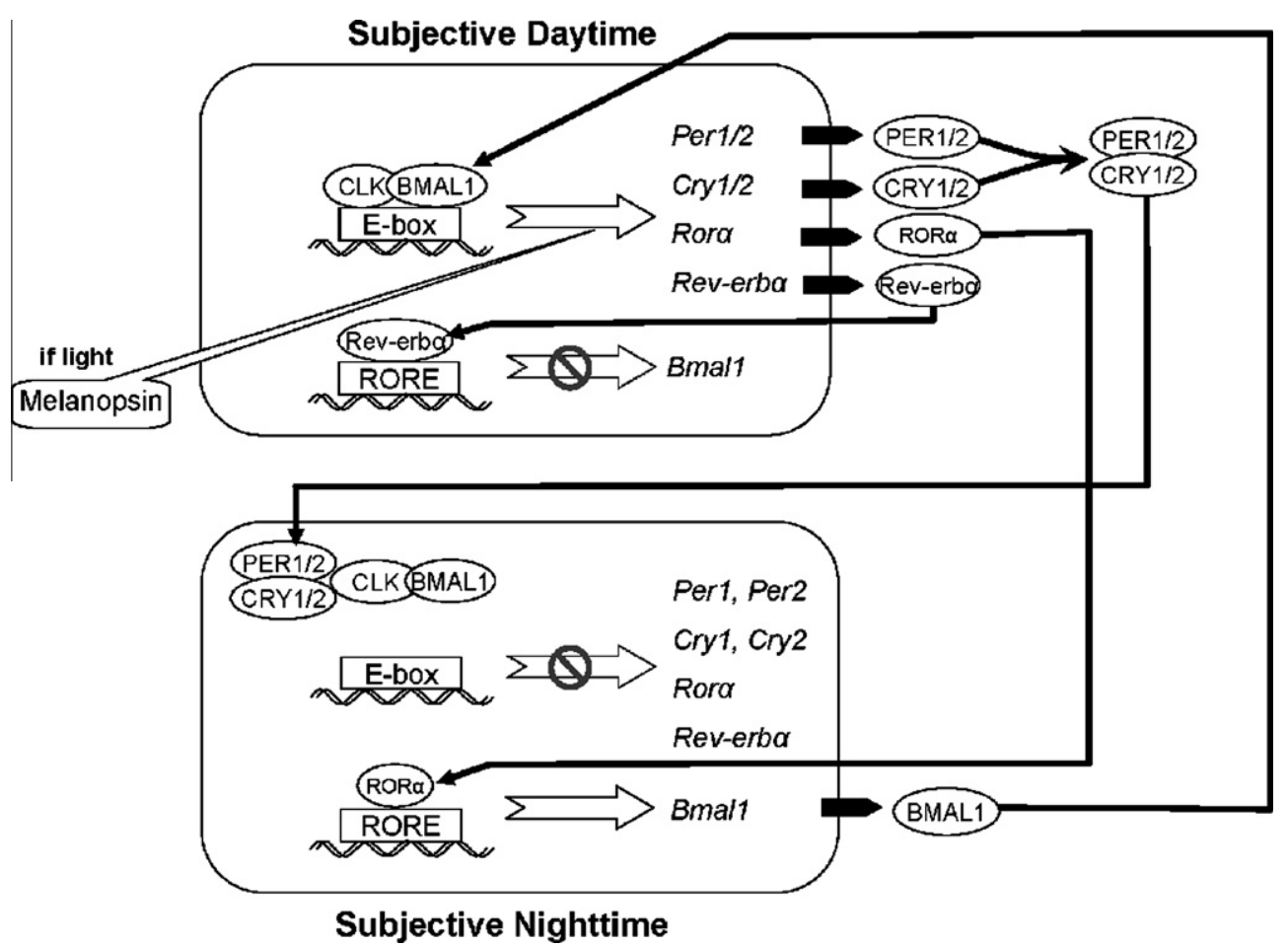

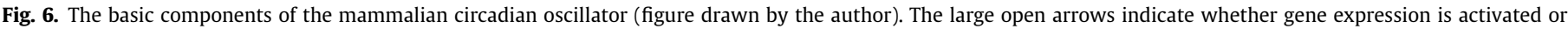

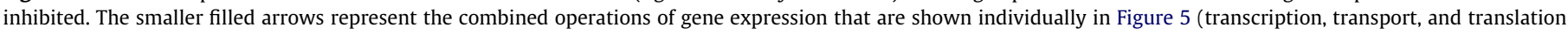

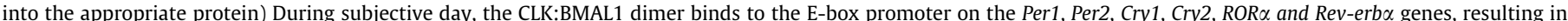

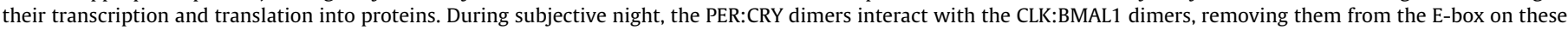
genes, stopping their expression. During subjective night, ROR $\alpha$ binds to the RORE promoter on the BMAL1 gene, increasing its transcription and translation. 
ods, ranging from 21.25 hours to 26.25 hours with a standard deviation of 1.25 hours. This high degree of variance was especially surprising since individual mice exhibit very little variation in circadian behavior in such activities as wheel running and suggested that the varying periods of individual neurons were coordinated in the behavior of the whole network within the SCN. Moreover, when Erik Herzog, Sara Aton, Rika Numano, Yoshiyuki Sakaki, and Hajime Tei (2004) maintained the pattern of neural connectivity in slices, they found much less variability, indicating that individual SCN neurons altered their behavior when they were connected to others. The same laboratory soon produced evidence pointing to vasoactive intestinal peptide (VIP) as the synchronizing agent.

Understanding the process of synchronization turned out to be a challenge. To begin with, the structure of the SCN is not homogenous-there are at least two different regions, a core region in which neurons produce VIP and are affected when the organism is exposed to light, and a shell in which neurons do not produce VIP but have receptors for it, and in which neurons are not directly affected by light (Silver, Schwartz, \& Michael, 2005). Oscillations in shell neurons, nonetheless, normally precede those in the core in phase (Welsh et al., 2010). However, when organisms experience phase advances (such as traveling multiple time zones to the east) they take many more days to reestablish the appropriate phase relation and during that time lag behind the core (Moore, Speh, \& Leak, 2002). A number of models have been advanced to try to understand how release and dissemination of VIP could generate the synchronization patterns found. The first assumed that VIP disseminated immediately to all other SCN neurons (Gonze et al., 2005), whereas subsequent models have tried to take the specific neural organization into account, as well as its consequences for synchronization (To et al., 2007; Vasalou et al., 2009).

In these investigations of synchrony between SCN cells, cells have again become the unit of study-it is cells that interact via VIP release with other cells and cells that are spatially organized in ways that affect synchronization. Researchers are focusing on how different cells behave differently as a result of the way they are connected to one another, and on how, as a result, they affect the behavior of other cells. Even though the models cited above in part utilize the equations developed to describe the behavior of genes and proteins within cells, they add to them terms and equations that characterize the coupling between cells. For example, Gonze et al. begin by adapting a model for an oscillator first proposed by Brian Goodwin (1963) to characterize the feedback process whereby the product of a reaction inhibits a step in its generation. The first (of three) equations in their adaptation of Goodwin's model characterizes for each cell $(i)$ how the change in concentration of per mRNA $\left(X_{i}\right)$ is affected by concentrations of nuclear PER $\left(Z_{i}\right)$ as well as the breakdown of per mRNA:

$\frac{d X_{i}}{d t}=v_{1} \frac{k_{1}^{n}}{Z_{i}^{n}+k_{1}^{n}}-v_{4} \frac{X_{i}}{k_{4}+X_{i}}$

They enhanced the model by, among other changes, adding a differential equation for the generation of VIP $(V)$ and an equation to determine its mean concentration $(F)$ across all $N$ cells:

$\frac{d V_{i}}{d t}=k_{7} X_{i}-v_{8} \frac{V_{i}}{k_{8}+V_{i}}$

$F=\frac{1}{N} \sum_{i=1}^{N} V_{i}$

Finally, they added terms to the first equation to characterize the effect of the mean concentration of VIP as well as light $(L)$ on the change in per mRNA:

$\frac{d X_{i}}{d t}=v_{1} \frac{k_{1}^{n}}{Z_{i}^{n}+k_{1}^{n}}-v_{4} \frac{X_{i}}{k_{4}+X_{i}}+v_{c} \frac{K F}{K_{c}+K F}+L$
In this model, and others that have been developed subsequently, the focus of the effort has turned to understanding the consequences of the processes that integrate individual cells into a network both for the reactions within the cells themselves and for the behavior of the population as a whole.

\section{Conclusion: from object to locus to object again}

It is generally true that in the wake of inquiry that focused on the cell as an object of study, much subsequent research pursued a reductionist path, focusing on the parts and operations within the cell and not the cell itself. Thus, I described the pattern in the nineteenth century in which, against the background of the cell theory that established the cell as the minimal unit exhibiting the features of life, many researchers directed their attention to the organelles within eukaryotic cells, especially the nucleus, and to structures within these organelles, such as the chromosomes within the nucleus. At the beginning of the twentieth century, biochemistry emerged as a discipline with techniques for explaining many basic physiological processes purely in terms of macromolecules, totally dispensing with the cell and its organelles (in fact, deliberately destroying cells and organelles in its preparations). Even when new techniques such as electron microscopy and cell fractionation allowed researchers to focus again on organelles, and researchers identified their field as cell biology, the cell remained a locus in which the workings of specific organelles could be studied.

I have argued, though, that there is a different perspective which focuses on the organization of components and orchestration of operations within the cell that jointly enable it to operate as an integrated system. This perspective treats the cell itself as an object of inquiry. When researchers ask how cells repair themselves, grow, and reproduce, they need not just to know about the component organelles or chemical systems, but how these are organized to enable the whole cell to perform these activities. In Gánti's chemoton, for example, the membrane is generated by the metabolic system, but it in turn regulates the egress of raw materials to the metabolic system and the expulsion of waste products. Even as cell biological research focuses on a broader range of subsystems, there remain the critical questions of how these are all coordinated so that the cell functions as an autonomous entity that maintains itself in a non-equilibrium relation with its environment.

Research on circadian rhythms provides a recent example in which, again, starting from the recognition that individual cells oscillate on an approximately twenty-four-hour cycle, research proceeded to decompose cells and identify the mechanism within them that enabled the cells to do so. But in this case the decomposition has been complemented by a recomposition as researchers recognized that individual cells synchronize their behavior with each other to maintain a regular oscillation. Understanding how they do this requires treating the individual cells as units and focusing on their interactions. This involves not just recognizing cells as highly organized systems (although that is part of the story), but how neurons are coordinated into a larger system. Recognizing both the integration of processes within cells, and the interaction between cells, requires focusing on the cell as the object of inquiry, not just the locus.

While often not attracting as much attention as decomposition, recomposition is a major research endeavor. Moreover, understanding how parts and operations interact with each other, especially when structured in an organized and constrained manner, is often a major challenge for scientists. Over the past two centuries biologists have developed sophisticated research techniques for decomposing systems into their components and analyzing the 
behavior of each. But sequentially examining the individual components and how they behave does not reveal how they interact. Despite the importance placed on understanding organization by many biologists, from Bernard (1865) to contemporary advocates of systems biology (Boogerd et al., 2007), we have far less understanding of the consequences of different non-sequential arrangement in which components can be organized, especially when they interact in a nonlinear fashion (Bechtel \& Richardson, 2010). Only recently have researchers begun to appreciate the complex dynamics that can arise when such systems are open to the influx of energy. Scientists have less developed tools for investigating organization. Although there are increasing efforts to build artificial systems with sophisticated organizational design in synthetic biology (Luisi, 2006; Elowitz \& Leibler, 2000), computational modeling is often the most powerful tool for understanding the effects of organization. Taking advantage of the increased computation power in contemporary computers, modelers are creating modeling platforms for investigating the effects of organization, but this project is still in its infancy.

One can expect that, as in the case of circadian rhythms, research on a variety of cellular phenomena (e.g., cell signaling) will eventually require recomposing decomposed systems and understanding how the whole cell behaves and relates to its environment, including structured systems in which it is contained. As important as research that focuses on parts and operations and treats cells as the locus of these is, it must be complemented by research that recomposes cells, addressing how they are organized and the operations performed within them are orchestrated. Such recomposition restores the cell to being an object of inquiry.

\section{Acknowledgements}

This paper was first presented at the Life of the Cell Workshop sponsored by the British Academy and Egenis, the ESRC Centre for Genomics in Society at the University of Exeter. I thank participants in the conference for their many helpful comments as well as members of the Philosophy of Biology Research Group at the University of California, San Diego (Daniel Burnston, Joyce Havstad, Alexandre Marcellesi, Eric Martin, Benjamin Sheredos, and Jacob Stegenga) for their valuable suggestions and comments. I extend special thanks to Maureen O'Malley, Staffan Müller-Wille and an anonymous reviewer for additional comments and suggestions on the penultimate draft.

\section{References}

Altmann, R. (1890). Die Elementaroganismen und ihre Beziehungen zu den Zellen. Leipzig: von Veit

Bechtel, W. (1984). The evolution of our understanding of the cell: A study in the dynamics of scientific progress. Studies in History and Philosophy of Science, 15, 309-356.

Bechtel, W. (1986). Biochemistry: A cross-disciplinary endeavor that discovered a distinctive domain. In idem (Ed.), Integrating scientific disciplines (pp. 77-100). Dordrecht: M. Nijhoff.

Bechtel, W. (2006). Discovering cell mechanisms: The creation of modern cell biology. Cambridge: Cambridge University Press.

Bechtel, W. (2009). Looking up, down, and around. Mechanistic explanation in psychology. Philosophical Psychology, 22, 543-564.

Bechtel, W., \& Abrahamsen, A. (2009). Decomposing, recomposing, and situating circadian mechanisms: Three tasks in developing mechanistic explanations. In H. Leitgeb, \& A. Hieke (Eds.), Reduction and elimination in philosophy of mind and philosophy of neuroscience (pp. 173-186). Frankfurt: Ontos.

Bechtel, W., \& Abrahamsen, A. (2010). Dynamic mechanistic explanation: Computational modeling of circadian rhythms as an exemplar for cognitive science. Studies in History and Philosophy of Science, 41(3).

Bechtel, W., \& Abrahamsen, A. (2011). Complex biological mechanisms: Cyclic, oscillatory, and autonomous. In Philosophy of complex systems. In C. A. Hooker (Ed.). Handbook of the Philosophy of Science (10). New York: Elsevier.

Bechtel, W., \& Richardson, R. C. (1993). Discovering complexity: Decomposition and localization as strategies in scientific research. Princeton, NJ: Princeton University Press.
Bechtel, W., \& Richardson, R. C. (2010). Introduction: Discovering complexityfurther perspectives. In eidem, Discovering complexity: Decomposition and localization as strategies in scientific research (2nd ed.). Cambridge, MA: MIT Press.

Benda, C. (1899). Weitere Mitteilungen über die Mitochondria. Archiv für Anatomie und Physiologie (Physiologische Abteilung), 376-383.

van Beneden, E. (1875). La maturation de l'œuf, la fécondation et les premières phases du développement embryonnaire des mammifères d'après des recherches faites chez le Lapin. Annuaire de l'Académie royale de Belgique, 40, 686-736.

Bernard, C. (1865). An introduction to the study of experimental medicine. New York: Dover.

Bichat, X. (1805). Recherches physiologiques sur la vie et la mort (3rd ed.). Paris: Machant.

Boogerd, F., Bruggeman, F. J., Hofmeyr, J.-H., \& Westerhoff, H. (Eds.). (2007). Systems biology: Philosophical perspectives. Amsterdam: Elsevier.

Bourne, G. H. (Ed.). (1942). Cytology and cell physiology. Oxford: Clarendon Press.

Brown, R. (1833). On the organs and mode of fecundation in Orchideae and Asclediadeae. Transactions of the Linnean Society, 16, 685-745.

Cannon, W. B. (1929). Organization of physiological homeostasis. Physiological Reviews, 9, 399-431.

Claude, A. (1940). Particulate components of normal and tumor cells. Science, 91, 77-78.

Cowdry, E. V. (1924). General cytology. Chicago: University of Chicago Press.

de Duve, C. (1963-1964). The separation and characterization of subcellular particles. Harvey Lectures, 59, 49-87.

De Robertis, E. D. P., Nowinski, W. W., \& Saez, F. (1960). General cytology (3rd ed.). Philadelphia: W. B. Saunders.

Doi, M., Hirayama, J., \& Sassone-Corsi, P. (2006). Circadian regulator CLOCK is a histone acetyltransferase. Cell, 125(3), 497-508.

Dutrochet, R. H. J. (1824). Recherches anatomiques et physiologiques sur la structure intime des animaux et des végétaux et sur leur motilité. Paris: J. B. Baillère.

Elowitz, M. B., \& Leibler, S. (2000). A synthetic oscillatory network of transcriptional regulators. Nature, 403(6767), 335-338.

Flemming, W. (1882). Zellsubstanz, Kern, und Zelltheilung. Leipzig: Vogel.

Fol, H. (1873). Le premier développement de l'oeuf chez les Géronidés. Archives des sciences physiques et naturelles, 2nd series, 48, 335-340.

Gánti, T. (2003). The principles of life. New York: Oxford.

Gitai, Z. (2005). The new bacterial cell biology: Moving parts and subcellular architecture. Cell, 120(5), 577-586.

Golgi, C. (1898). Intorno alla struttura delle cellule nervose. Bollettino della Società medico-chirurgica di Pavia, 13, 3-16.

Gonze, D., Bernard, S., Waltermann, C., Kramer, A., \& Herzel, H. (2005). Spontaneous synchronization of coupled circadian oscillators. Biophysical Journal, 89(1), 120-129.

Goodwin, B. C. (1963). Temporal organization in cells; a dynamic theory of cellular control processes. London: Academic.

Griesemer, J. R., \& Szathmáry, E. (2008). Gánti’s chemoton model and life criteria. In S. Rasmussen, L. Chen, N. Packard, M. Bedau, D. Deamer, P. Stadler, \& D. Krakauer (Eds.), Protocells: Bridging nonliving and living matter (pp. 407-432). Cambridge, MA: MIT Press.

Hardin, P. E., Hall, J. C., \& Rosbash, M. (1990). Feedback of the Drosophila period gene product on circadian cycling of its messenger RNA levels. Nature, 343(6258), 536-540.

Herzog, E. D., Aton, S. J., Numano, R., Sakaki, Y., \& Tei, H. (2004). Temporal precision in the mammalian circadian system: A reliable clock from less reliable neurons. Journal of Biological Rhythms, 19(1), 35-46.

Hogeboom, G. H., Claude, A., \& Hotchkiss, R. D. (1946). The distribution of cytochrome oxidase and succinoxidase in the cytoplasm of the mammalian liver cell. Journal of Biological Chemistry, 165, 615-629.

Hooke, R. (1665). Micrographia: Or some physiological descriptions of minute bodies made by magnifying glasses with observations and inquiries thereupon. London: J. Martin and J. Allestry.

Jamieson, J. D., \& Palade, G. E. (1966). Role of the Golgi complex in the intracellular transport of secretory proteins. Proceedings of the National Academy of Sciences of the United States of America, 55, 424-431.

Konopka, R. J., \& Benzer, S. (1971). Clock mutants of Drosophila melanogaster. Proceedings of the National Academy of Sciences of the United States of America, 89, 2112-2116.

Leeuwenhoek, A. van. (1674). More observations from Mr. Leewenhook, in a letter of Sept. 7, 1674, sent to the publisher. Philosophical Transactions of the Royal Society of London, 9, 178-182.

Leloup, J.-C., \& Goldbeter, A. (2003). Toward a detailed computational model for the mammalian circadian clock. Proceedings of the National Academy of Sciences of the United States of America, 100(12), 7051-7056.

Luisi, P. L. (2006). The emergence of life: From chemical origins to synthetic biology. Cambridge: Cambridge University Press.

Maturana, H. R., \& Varela, F. J. (1980). Autopoiesis and cognition: The realization of the living. Dordrecht: D. Reidel.

Michaelis, L. (1899). Die vitale Färbung, eine Darstellungsmethode der Zellgranula. Archiv für mikroskopische Anatomie, 55, 558-575.

Moore, R. Y., \& Eichler, V. B. (1972). Loss of a circadian adrenal corticosterone rhythm following suprachiasmatic lesions in the rat. Brain Research, 42, 201-206.

Moore, R. Y., Speh, J. C., \& Leak, R. K. (2002). Suprachiasmatic nucleus organization. Cell and Tissue Research, 309, 89-98. 
Novikoff, A. B., Beaufay, H., \& de Duve, C. (1956). Electron microscopy of lysosomerich fractions from rat liver. Journal of Biophysical and Biochemical Cytology, 2(4/ 2), 179-184.

Palade, G. E. (1952). The fine structure of mitochondria. Anatomical Record, 114, $427-451$.

Palade, G. E., \& Claude, A. (1949a). The nature of the Golgi apparatus. I. Parallelism between intercellular myelin figures and Golgi apparatus in somatic cells. Journal of Morphology, 85, 35-69.

Palade, G. E., \& Claude, A. (1949b). The nature of the Golgi apparatus. II. Identification of the Golgi apparatus with a complex of myelin figures. Journal of Morphology, 85, 71-111.

Palade, G. E., \& Siekevitz, P. (1955). Liver microsomes: An integrated morphological and biochemical study. Journal of Biophysical and Biochemical Cytology, 2, 171-200.

Porter, K. R., Claude, A., \& Fullam, E. F. (1945). A study of tissue culture cells by electron microscopy. Journal of Experimental Medicine, 81, 233-255.

Ralph, M. R., Foster, R. G., Davis, F. C., \& Menaker, M. (1990). Transplanted suprachiasmatic nucleus determines circadian period. Science, 247(4945), 975-978.

Remak, R. (1855). Untersuchungen über die Entwicklung der Wirbelthiere. Berlin: Reimer.

Rosen, R. (1991). Life itself: A comprehensive inquiry into the nature, origin, and fabrication of life. New York: Columbia.

Ruiz-Mirazo, K., Peretó, J., \& Moreno, A. (2004). A universal definition of life: Autonomy and open-ended evolution. Origins of Life and Evolution of the Biosphere, 34, 323-346.

Schleiden, M. J. (1838). Beiträge zur Phytogenesis. Archiv für Anatomie, Physiologie und wissenschaftliche Medicin, 137-176.
Schultze, M. (1861). Über Muskelkörperchen und das, was man eine Zelle zu nennen habe. Müllers Archiv für Anatomie, Physiologie, und wissenschaftliche Medicin, 1-27.

Schwann, T. (1836). Über das Wesen des Verdauungsprocesses. Archiv für Anatomie, Physiologie und wissenschaftliche Medicin, 90-138.

Schwann, T. (1839). Mikroskopische Untersuchungen über die Übereinstimmung in der Struktur und dem Wachstrum der Theire und Planzen. Berlin: Sander.

Silver, R., Schwartz, W. J., \& Michael, W. Y. (2005). The suprachiasmatic nucleus is a functionally heterogeneous timekeeping organ. Methods in Enzymology, 393, 451-465.

To, T.-L., Henson, M. A., Herzog, E. D., \& Doyle, F. J., III. (2007). A molecular model for intercellular synchronization in the mammalian circadian clock. Biophysical Journal, 92(11), 3792-3803.

Varela, F. J. (1979). Principles of biological autonomy. New York: Elsevier.

Vasalou, C., Herzog, E. D., \& Henson, M. A. (2009). Small-world network models of intercellular coupling predict enhanced synchronization in the suprachiasmatic nucleus. Journal of Biological Rhythms, 24(3), 243-254.

von Mohl, H. (1846). On the circulation of the sap in the interior of cells. The Annals and Magazine of Natural History, 116, 1-10.

Welsh, D. K., Logothetis, D. E., Meister, M., \& Reppert, S. M. (1995). Individual neurons dissociated from rat suprachiasmatic nucleus express independently phased circadian firing rhythms. Neuron, 14(4), 697-706.

Welsh, D. K., Takahashi, J. S., \& Kay, S. A. (2010). Suprachiasmatic nucleus: Cell autonomy and network properties. Annual Review of Physiology, 72(1).

Wöhler, F. (1839). Das enträthselte Geheimniss der geistigen Gährung. Annalen der Pharmacie, 29, 100-104. 